\title{
Increased V/D-ratio in lumbosacral SEP's as a new electrophysiological measure of spasticity
}

\author{
J Rösche*,1 and E Mauch ${ }^{2}$ \\ ${ }^{I}$ Department of Neurology and Epileptology (Department of Psychiatry I, University of Ulm), Ravensburg- \\ Weissenau, Germany; ${ }^{2}$ Neurological Hospital Dietenbronn (Academic Hospital University of Ulm), D-88477 \\ Schwendi, Germany
}

\begin{abstract}
Study Design: Open-label, prospective study.
Objective: To establish the amplitude-ratio of V-response and D-response (V/D-ratio) as a new measure of spasticity, comparing the motor effect of the H-reflex to the sensoric input. Methods: In 13 legs of seven patients with spasticity and in four legs of patients without central nervous system disease, maximal M-response and maximal H-reflex were recorded. Lumbosacral SEP's were recorded with the same stimulus parameters as the maximal H-reflex. $\mathrm{H} / \mathrm{M}$-ratio and $\mathrm{V} / \mathrm{D}$-ratio were compared to the increased muscle tone.

Results: The $\mathrm{H} / \mathrm{M}$-ratio and the $\mathrm{V} / \mathrm{D}$-ratio in legs with spasticity differed significantly from the $\mathrm{H} / \mathrm{M}$-ratio and the V/D-ratio in normal legs. But only the V/D-ratio was higher in legs with moderately or highly increased muscle tone than in legs with slightly increased muscle tone.

Conclusion: The V/D-ratio increases in spasticity and shows an even closer relationship to increased muscle tone than the $\mathrm{H} / \mathrm{M}$-ratio.

Spinal Cord (2000) 38, 287-291
\end{abstract}

Keywords: ventral root response; dorsal root response; H-reflex; spasticity

\section{Introduction}

Several electrophysiological methods are known to be suitable for the evaluation of the basic segmental pathophysiological mechanisms of spasticity. ${ }^{1}$ F-waves are motor responses produced by antidromic activation of motoneurons following stimulation of motor axons peripherally. The F-wave-amplitude parameters (e.g. the F-wave maximal amplitude, the mean F-wave amplitude, the ratio of $\mathrm{F}$-wave to M-response maximal amplitudes $\left(\mathrm{F}_{\max } / \mathrm{M}\right)$ and the ratio of $\mathrm{F}$ wave mean to $\mathrm{M}$-response maximal amplitudes $\left(\mathrm{F}_{\text {mean }} /\right.$ M)) can be used for the assessment of alpha motoneurone activity. ${ }^{2}$ The response of the ankle tendon-reflex can be studied utilizing a hand-held electronic reflex hammer that triggers the sweep of a standard EMG apparatus. ${ }^{3}$ The H-reflex is a reflex response in calf muscles following submaximal stimulation of the posterior tibial nerve. The reflex arc of the H-reflex includes input from large, fast conducting Ia fibers. The H-reflex does not include muscle spindle activation. ${ }^{4}$ So the amplitude ratio of the tendon-reflex to the H-reflex (TA/H-ratio) can be used for the

*Correspondence: J Rösche, Die Weissenau, Department of Neurology and Epileptology (Department of Psychiatry I, University of Ulm) Weingartshoferstrasse 2, D-88214 RavensburgWeissenau, Germany assessment of gamma motoneurone activity. ${ }^{1}$ Flexor reflexes are polysynaptic sensorimotor mechanisms causing withdrawal of skin areas from a potentially offending stimulus. The flexor reflex evoked in the tibialis anterior muscle by stimulation of the medial plantar nerve can be used for the assessment of common interneurone activity. ${ }^{1}$ Due to a presynaptic inhibition of spindle Ia afferents the vibration of the Achilles tendon inhibits the H-reflex of the soleus muscle for the duration of vibration. Because presynaptic inhibition is reduced with upper motoneuron lesions the amplitude ratio of the H-reflex during vibration of the Achilles tendon to the maximum $\mathrm{H}$ reflex $\left(\mathrm{H}_{\text {vibrated }} / \mathrm{H}_{\text {maximal }}\right)$ can be used for the assessment of presynaptic inhibition. ${ }^{1}$ The ratio of maximum $\mathrm{H}$ reflex to maximum $\mathrm{M}$-response is also known to be a measure of spasticity. ${ }^{5}$ It has been argued ${ }^{6}$ that this ratio is even more sensitive to changes in motoneuronal excitability than the F-responses.

On the other hand, despite clinically decreased muscle tone the ratio was not influenced by several different pharmacological antispastic therapies, ${ }^{7}$ whereas the F-wave-amplitudes were reduced by physical therapy. 8 ,9 Thus F-wave-amplitude-parameters are regarded to be more precise for the assessment of motoneuronal excitability than the Tand H-reflexes. ${ }^{2}$ Nevertheless a reanalysis of the data from the studies on the effect of physical 
therapy $^{8,9}$ revealed that about half of the spastic patients under medication had normal F-waveamplitudes and increased muscle tone. So there is a need for other electrophysiological parameters for documenting spasticity. There are hints that $\mathrm{M}$ amplitudes are decreased by central lesion. In a group of patients with spastic hyperreflexia studied by Fisher, ${ }^{10}$ the amplitudes of M-responses were significantly $(P<0.005) \quad$ decreased compared to normal controls. The reason for this decrease in M-amplitudes has not been established, but a tendency for lower M-amplitudes in patients with central lesions has been observed by other authors as well. ${ }^{11-15}$ Therefore there should be an attempt to establish an amplitude-ratio, which is not dependent on muscle responses. This should be possible with the use of lumbosacral somatosensory evoked potentials (SEP).

After the stimulation of the tibial nerve in the popliteal fossa two different negative lumbosacral potentials were recorded at the L5 spinous processus (dorsal-root $=\mathrm{D}$-response; ventral-root $=\mathrm{V}$-response) . 16,17 The second potential (V-response) showed similar response characteristics to the H-reflex. The second potential appeared alone at the L4 level when the stimulus intensity was adjusted to elicit a well defined H-reflex response but a minimal direct muscle response. Increasing the stimulus strength further caused the first potential to appear and a maximal stimulus caused the ventral-root potential to decrease while the dorsal-root potential increased. The ventral root potential tended to have longer latency when recorded from more caudal levels (e.g. level L5 or S1). ${ }^{16}$ Nevertheless some authors thought it to be a volume-conducted spinal cord activity. ${ }^{18,19}$ However it could be shown that only the V-response at the L5 spinous processus and not the spinal cord activity (Sresponse) at the Th12 or L1 spinous processus was suppressed by vibration of the Achilles tendon like the H-reflex. So the ventral root wave most likely represents reflex outflow in motor axons through the ventral roots. ${ }^{20}$ It was shown that the lumbosacral SEP remained stable for more than a year in healthy volunteers and in patients with nonprogressive neurological disorders. ${ }^{21}$ Several authors published recruitment curves. ${ }^{17,20,22} \mathrm{Stöhr}^{22}$ analyzed the lumbosacral SEP in a healthy volunteer using stimulus intensities of 18,28 and $60 \mathrm{~mA}$. With a stimulus intensity of $18 \mathrm{~mA}$ he produced no M-response, an inconstant H-reflex, a clear-cut D-response and a very small V-response. A stimulus intensity of $28 \mathrm{~mA}$ evoked a small M-response, a maximal H-reflex amplitude, and a clear-cut D-response and Vresponse. At the maximal stimulus intensity of $60 \mathrm{~mA}$ the amplitude of the D-response increased but the Vresponse was so small that it was hard to identify.

In this study we tried to establish the amplituderatio of V-response to D-response (V/D-ratio) as a new measure of spasticity. $\mathrm{H} / \mathrm{M}$-ratio and $\mathrm{V} / \mathrm{D}$-ratio reflect different aspects of the reflex volley in the lower extremities. The $\mathrm{H} / \mathrm{M}$-ratio reflects the efferent effect of the H-reflex in comparison to the highest possible effect, saying nothing about the afferent input. In fact the muscle response produced by the reflex volley is compared to the direct muscle response produced by maximal stimulation. The $\mathrm{V} / \mathrm{D}$-ratio compares the motoric output of the reflex volley estimated by the amplitude of the ventral root potential to the sensoric input estimated by the amplitude of the dorsal root potential of the lumbosacral somatosensory-evoked potentials.

\section{Methods}

Thirteen legs of seven patients with spasticity due to multiple sclerosis and four legs of three patients without central nervous system disease were investigated. All patients had given informed consent. Spasticity was clinically rated according to the modified Ashworth scale. ${ }^{23}$ During the rating the patients were in a lying position. During the electrophysiological recording they lay supine on a couch. The maximal M-response and maximal H-reflex were recorded from the calf muscle using a stimulus pulse of $0.5 \mathrm{~ms}$ duration and a stimulus frequency of $0.2 \mathrm{~Hz}$ for the H-reflex. Lumbosacral SEP's were recorded with the same stimulus parameters as the maximal H-reflex. Stimulus intensity was $17.65 \mathrm{~mA}$ on the average $(\mathrm{SD}=10.2 \mathrm{~mA})$. This is high above the sensory threshold, which is usually at a stimulus intensity of some $4 \mathrm{~mA} .^{24}$ The recording electrode was placed on the spinous processus at L5, the reference electrode was placed over the contralateral bony prominence of the anterior superior iliac spine. The potentials were recorded using a 'Toennies multiliner' with a bandpass of $100-3000 \mathrm{~Hz}$. Twohundred responses were averaged per trial. Two trials were performed on each leg, so the electrophysiological procedure took about $60 \mathrm{~min}$ for each leg. Therefore the electrophysiological procedure was performed in separate sessions for each leg. The amplitudes of the negative $\mathrm{D}$ - and $\mathrm{V}$-responses were measured against the next positivities. Then the mean of the amplitudes of the D- and V-responses of the two trials was taken into consideration. $\mathrm{H} / \mathrm{M}$-ratio and V/D-ratio were compared to the rating of the increased muscle tone. Statistics were performed with the $U$-test (MannWhitney-Wilcoxon two sample statistics).

\section{Results}

In the 13 legs with spasticity, the muscle tone was rated in four legs as slightly increased (Ashworth scale 1), in four legs as moderately increased (Ashworth scale 2), in four legs as highly increased (Ashworth scale 3) and one leg was rigid in extension (Ashworth scale 4). All patients with spasticity had severe hyperreflexia with cloni.

The $\mathrm{H} / \mathrm{M}$-ratio in legs with spasticity was $41.73 \%$ (SD $14.65 \%)$. This differed significantly $(P=0.02)$ from the $\mathrm{H} / \mathrm{M}$-ratio in normal legs (mean $17.88 \%$ 
SD $13.42 \%$ ). However the $\mathrm{H} / \mathrm{M}$-ratio was not significantly higher in legs with moderately or highly increased muscle tone than in legs with slightly increased muscle tone (see Figure 1).

The V/D-ratio in legs with spasticity was $119.22 \%$ (SD 71.54\%). This differed significantly $(P=0.01)$ from the V/D-ratio in normal legs (mean $44.00 \% \mathrm{SD}$ $12.72 \%)$. It was also higher $(P=0.05$; for examples see Figure 2, for all data see Figure 3) in legs with moderately increased muscle tone (Ashworth scale 2) and in legs with highly increased muscle tone (Ashworth scale 3) than in legs with slightly increased muscle tone (Ashworth scale 1).

$\mathrm{H} / \mathrm{M}$-ratio and V/D-ratio were significantly correlated $(r=0.6 ; P=0.01$; see Figure 4$)$. Stimulus intensity was $17.54 \mathrm{~mA}(\mathrm{SD}=11.22 \mathrm{~mA})$ in legs with spasticity and $18 \mathrm{~mA}(\mathrm{SD}=7.12 \mathrm{~mA})$ in legs without spasticity. There was no significant correlation between stimulus intensity and A/D-ratio $(r=0.01 ; P=0.97)$.

Latencies in legs with spasticity were $30.12 \mathrm{~ms}$ (SD $2.83 \mathrm{~ms}$ ) for the H-reflex, $10.93 \mathrm{~ms}$ (SD $0.71 \mathrm{~ms}$ ) for the dorsal root response and $15.39 \mathrm{~ms}$ (SD $0.96 \mathrm{~ms}$ ) for the ventral root response. There were no significant differences to the latencies of H-reflex (mean $29.4 \mathrm{~ms}$, SD $2 \mathrm{~ms}$ ), dorsal root response (mean $10.85 \mathrm{~ms}$ SD $0.33 \mathrm{~ms}$ ) and ventral root response (mean $15.51 \mathrm{~ms}$, SD $0.65 \mathrm{~ms}$ ) in legs without spasticity.

\section{Conclusion}

Lumbosacral SEPs are difficult to record. In our group of patients we managed to record stable somatosensory-evoked potentials perhaps because the lower limit of our bandpass was raised to a frequency of $100 \mathrm{~Hz}$.

To our knowledge two studies have investigated lumbosacral SEP in spasticity. ${ }^{25,26}$ They did not consider the amplitude of the V-response and discussed only the spinal cord response with partially

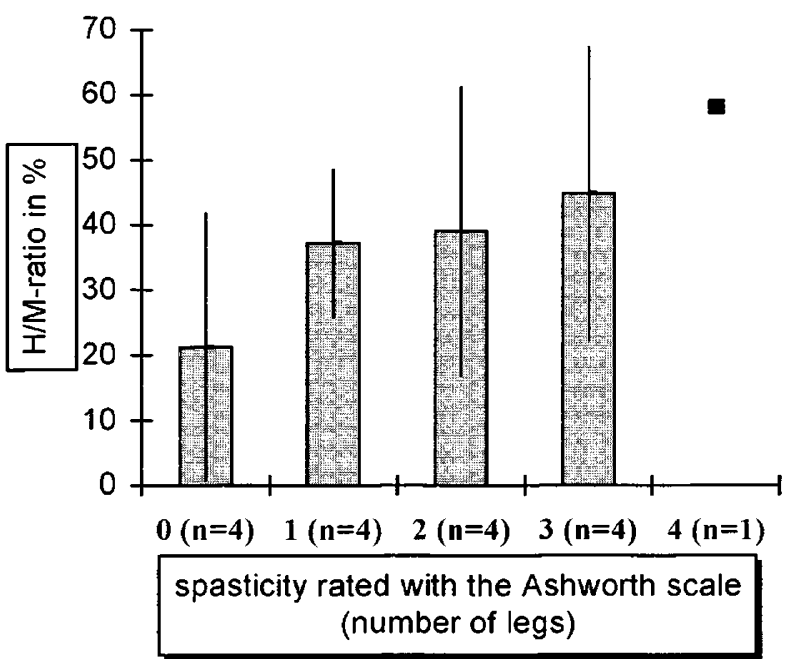

Figure $1 \mathrm{H} / \mathrm{M}$-ratio in the different degrees of spasticity: mean +2.5 SEM; $\square$ mean -2.5 SEM contradictory results. So our study is the first to consider the variation of the V-response under the influence of spasticity.

The lumbosacral V/D-ratio is increased in spasticity and shows an even closer relationship to increased muscle tone than the $\mathrm{H} / \mathrm{M}$-ratio. This is perhaps due to the fact that the $\mathrm{H} / \mathrm{M}$-ratio picks up the efferent reflex volley only in the soleus muscle while the $\mathrm{V}$ response reflects a more global output to many different muscles. This is exaggerated in spasticity. Nevertheless the V/D-ratio is significantly correlated
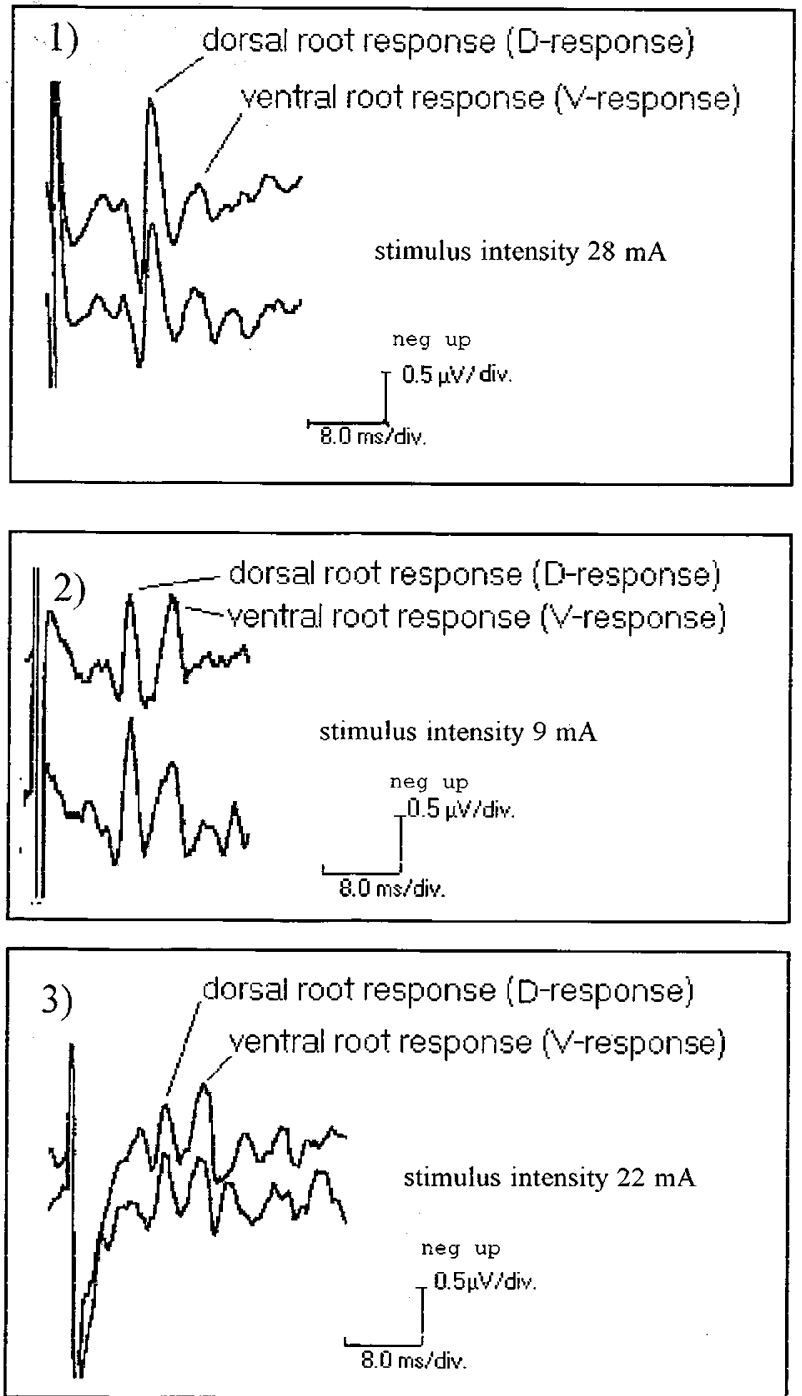

Figure 2 Lumbosacral-evoked potentials recorded at the L5 spinous processus after stimulation of the tibial nerve over the popliteal fossa. The results of two trials in each leg superimposed, negative potentials displayed upward (neg up): (1) lumbosacral-evoked potentials in a leg without spasticity (V/D-ratio 35\%); (2) lumbosacral-evoked potentials in a leg with slightly increased muscle tone (Ashworth scale 1; V/Dratio $71.78 \%$ ); (3) lumbosacral-evoked potentials in a leg with highly increased muscle tone (Ashworth scale 3; V/D-ratio $142.74 \%$ ) 


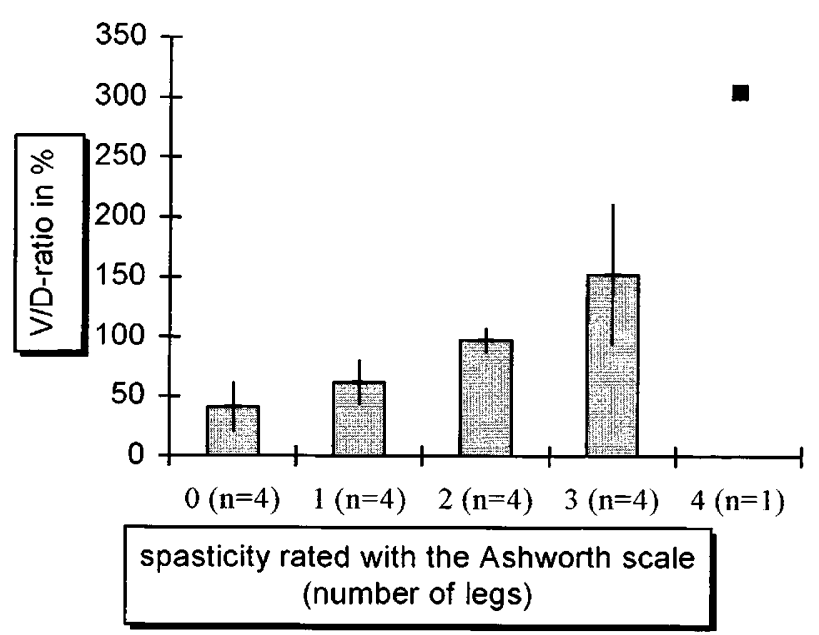

Figure $3 \mathrm{~V} / \mathrm{D}$-ratio in the different degrees of spasticity: mean +2.5 SEM; $\square$ mean -2.5 SEM

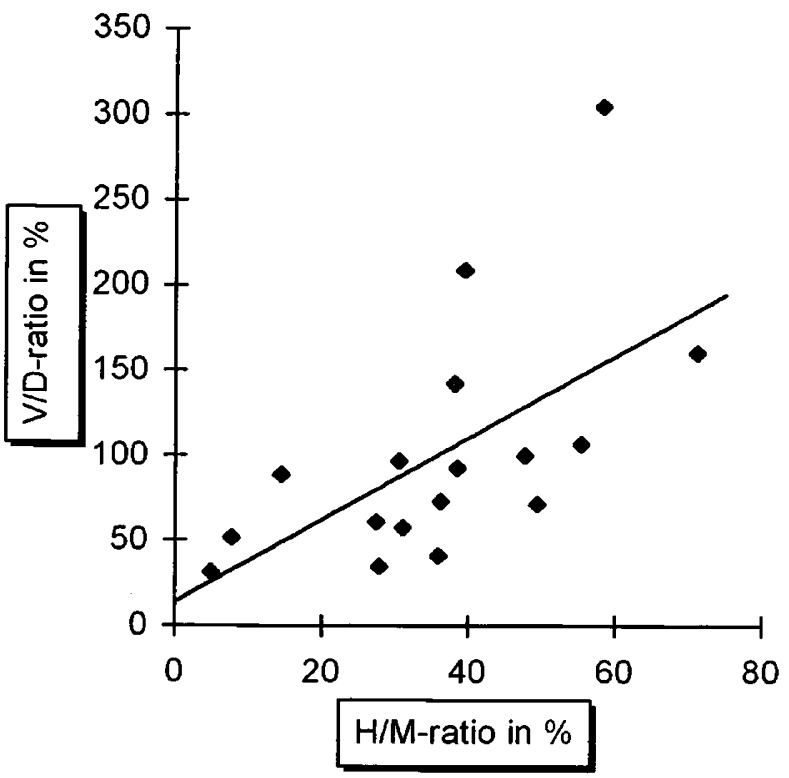

Figure 4 Correlation of $\mathrm{H} /$ M-ratio with $\mathrm{V} / \mathrm{D}$-ratio $(\mathrm{r}=0.6)$

to the $\mathrm{H} / \mathrm{M}$-ratio. The ventral root response most likely reflects the efferent reflex volley in alpha motoneurons. But it is not clear how far the dorsal root response reflects the afferent volley of the $\mathrm{H}$ reflex. Since a normal spinal response at L1 was found in patients with Adie-Syndrome and absent $\mathrm{H}$ reflex $^{27,28}$ there should be no major contribution of Ia sensory fibres to the spinal response at L1. It remains uncertain how much they contribute to the dorsal root response at $\mathrm{L} 5$.

Further studies are needed to elucidate the basic pathophysiological mechanism which is reflected by the increased V/D-ratio in spasticity, but the V/D-ratio can now be used to document spasticity and to monitor antispastic therapy.

\section{References}

1 Milanov I. Examination of segmental pathophysiological mechanisms of spasticity. Electromyogr Clin Neurophysiol 1994; 34: $73-79$.

2 Milanov GI. F-wave for assessment of segmental motoneurone excitability. Electromyogr Clin Neurophysiol 1992; 32: 11-15.

3 Kurouglu R, Oh SJ. Quantitation of tendon reflexes in normal volunteers. Electromyogr Clin Neurophysiol 1993; 33: $347-351$.

4 Fisher MA. AAEM Minimonograph \#13: H-reflexes and F waves: Physiology and clinical indications. Muscle Nerve 1992; 15: $1223-1233$.

5 Matthews WB. Ratio of maximum H-reflex to maximum Mresponse as a measure of spasticity. J Neurol Neurosurg Psychiatr 1966; 29: $201-204$.

6 Hultborn H, Nielsen JB. H-reflexes and F-responses are not equally sensitive to changes in motoneuronal excitability. Muscle Nerve 1995; 18: 1471 - 1474

7 Milanov GI. A comparison of methods to assess the excitability of lower motoneurones. Can J Neurol Sci 1992; 19: 64-68.

8 Rösche J, et al. Effects of physiotherapy on F-wave-amplitudes in spasticity. Electromyogr Clin Neurophysiol 1996; 36: 509-511.

9 Rösche J, et al. The effects of therapy on spasticity utilizing a motorized exercise-cycle. Spinal Cord 1997; 35: 176-178.

10 Fisher MA. F/M ratios in polyneuropathy and spastic hyperreflexia. Muscle Nerve 1988; 11: 217-222.

11 McComas AJ, Sica REP, Upton ARM, Aquilera N. Functional changes in motoneurons of hemiparetic patients. J Neurol Neurosurg Psychiatr 1973; 36: $183-193$.

12 Namba T, Schuman MH, Grob D. Conduction velocity in the ulnar nerve in hemiplegic patients. J Neurol Sci 1971; 12: $177-$ 186.

13 Taylor RG, Kewalramani LS, Fowler WM. Electromyographic findings in lower extremities of patients with high spinal cord injury. Arch Phys Med Rehabil 1974; 55: 16-23.

14 Taylor S, Ashby P, Verrier M. Neurophysiological changes following traumatic spinal lesions in man. J Neurol Neurosurg Psychiatr 1984; 47: $1102-1108$.

15 Weaver RA, Landau WM, Higgins JF. Fusimotor function. Arch Neurol 1963; 9: $37-42$.

16 Delbeke J, McComas AJ, Kopec SJ. Analysis of evoked lumbosacral potentials in man. J Neurol Neurosurg Psychiatr 1978; 41: $293-302$.

17 Dimitrijevic MR, Larsson LE, Lehmkuhl D, Sherwood A. Evoked spinal cord and nerve root potentials in humans using a non-invasive recording technique. Electroenceph Clin Neurophysiol 1978; 45: $331-340$.

18 El-Negamy E, Sedgwick EM. Properties of a spinal somatosensory evoked potentials recorded in man. J Neurol Neurosurg Psychiatry 1978; 41: $762-768$.

19 Phillips LH, Daube JR. Lumbosacral spinal evoked potentials in humans. Neurology 1980; 30: $1175-1183$.

20 Yiannikas C, Shahani BT. The origins of lumbosacral spinal evoked potentials in humans using a surface electrode recording technique. J Neurol Neurosurg Psychiatr 1988; 51: 499-508.

21 Beric A. Stability of lumbosacral somatosensory evoked potentials in a long-term follow-up. Muscle Nerve 1988; 11: $621-626$

22 Stöhr M. Somatosensible Reizantworten von Rückenmark und Gehirn (SEP). In: Stöhr M, Dichgans J, Buettner UW, Hess ChW, Altenmüller E (eds). Evozierte Potentiale. 3rd edn. Springer: Berlin, Heidelberg, New York 1996, pp 23-288.

23 Bohannon RW, Smith MB. Interrater reliability of a modified Ashworth scale of muscle spasticity. Physical Therapy 1987; 67: $206-207$.

24 Jörg J. SEP in der neurologischen Diagnostik und Therapie. In: Jörg J, Hielscher $\mathrm{H}$ (eds). Evozierte Potentiale in Klinik und Praxis. 3rd edn. Springer: Berlin, Heidelberg, New York 1993, pp $144-244$ 
25 Delwaide PJ, Schoenen J, De Pasqua V. Lumbosacral spinal evoked potentials in patients with multiple sclerosis. Neurology 1985; 35: 174-179.

26 Kofler M, Donovan WH, Loubser PG, Beríc A. Effects of intrathecal baclofen on lumbosacral and cortical somatosensory evoked potentials. Neurology 1992; 42: $864-868$.
27 Pavesi G et al. On the cause of tendon areflexia in the HolmesAdie syndrome. Electromyogr Clin Neurophysiol 1994; 34: 111 115.

28 Rösche J, Maurer H, Schreiber H, Kornhuber HH. Normale somato-sensibel evozierte Potentiale beim Adie-Syndrom. Die Rolle der Ia-Fasern. Z EEG-EMG 1997; 28: 49 - 51. 